\title{
A new efficient and environmentally friendly deodorant floor drain
}

\author{
Liyao Bu
}

\author{
School of North China Electric Power University , Baoding 071000, China. \\ 303068677@qq.com
}

\begin{abstract}
Keywords: Floor drain, deodorant, water-sealed, mechanical, spring, human health, Energy Saving and Emission Reduction.
\end{abstract}

\begin{abstract}
Floor drain is mainly used in bathroom and kitchen, play the role of drainage. However, after deodorant floor drain device failure, it becomes a floor drain vent, sewer smell manure elements, carbon monoxide, methane, hydrogen sulfide and other poisonous gases emitted into the interior space of the human health hazard. Nowadays the market has been commonly used to drain on the existence of the above problems, in terms of performance, there are some drawbacks, especially in anti-odor, overflow, seepage, etc., not only cause great inconvenience in use, for frequent cleaning and replacement of unnecessary waste of manpower, material and financial resources, but also affect the indoor air quality, endangering people's health. Through existing floor drain on the market of the advantages and disadvantages of the use of theoretical calculations and experimental verification, design a new efficient and environmentally friendly deodorant floor drain. This product uses water-sealed and mechanical combination, in favor of emissions while enhancing floor drain deodorant performance.
\end{abstract}

\section{Introduction}

\subsection{Background.}

Floor drain is an important interface sewerage system and indoor ground, as an important part residential drainage system, its performance directly affects the indoor air quality of the bathroom and kitchen odor control is very important.

Floor drain has been the home renovation neglected aspect, although it is very often minor, but it can be a small drain directly affect the normal human living environment. Most home have experienced indoor smell, but we do not know where it comes from. This is ignored by everyone of the floor drain back to taste, but also a serious hit back sewage overflow, bugs, cockroaches, rats from climbing out of the floor drain. After deodorant floor drain device failure, floor drain into the vent, sewer smell manure elements, carbon monoxide, methane, hydrogen sulfide and other poisonous gases emitted into the interior space of the human health hazard.

\subsection{Significance.}

As early as 2001, two Vice-Premier had 3 consecutive instructions, pointing out issues related indoor environmental health of residents, we must attach great importance to and instructed relevant departments to study. According to the relevant data demonstrate that the air can be detected in more than 300 kinds of pollutants, about $68 \%$ of human diseases and indoor pollution. Mainly through the cooling water, air supply pipes, faucets, shower, air conditioning cooling towers and other ways of spreading Legionella pneumophila, Legionnaires disease have occurred so far in the country seven times, the incidence of pain, hurt lives. 2003 Hong Kong Amoy Gardens SARS is unqualified floor drain angered disaster, once again confirms the importance of the floor drain. China Interior Decoration Association Guangsheng Song, director of analysis, indoor environmental pollution is mainly caused by the use of improper decoration materials. First, the design is unreasonable, the second process is unreasonable, the third is poor choice of decoration materials. Today the market has been commonly used to drain on the existence of the above-mentioned several problems, in terms of performance, there are some drawbacks, especially in anti-odor, overflow, seepage, etc., not only cause great inconvenience in the use of, for frequent cleaning and replacement of unnecessary waste 
of manpower, material and financial resources, but also affect the indoor air quality, endangering people's health.

Experts estimate that the average time per day in a modern interior is 6-9 times more time outdoors, and indoor air pollution than outdoor seriously to 70 times. Therefore, deodorant floor drain improve the performance of great significance. For these phenomena, the proposed transformation of designing a new efficient and environmentally friendly deodorant floor drain. Various performance factors, materials, aesthetics, economy, etc., to achieve fast drainage, anti-odor, anti-clogging, easy to clean, long life effect, and applies to a variety of places, including general industrial and civil buildings, to reduce kitchen and toilet floor drain back to taste, to home "reduction" effect and improve indoor air quality, protect their health and reduce the blockage for the maintenance of human, material and financial resources, energy conservation, the benefit of the people.

\section{Design}

\subsection{Structural Design.}

Comprehensive comparison of the floor drain core currently on the market, we found that over time its performance decreases rapidly deodorant, this project seeks to improve the existing floor drain core, in favor of emissions while enhancing floor drain deodorant performance. This product uses water-sealed and mechanical combination of improved mechanical deodorizing device, ensuring deodorizing effect, while cost savings, while improving device stability, long life, low maintenance replacement rate, thereby achieve emissions at home, optimizing the indoor environment, safeguarding human health, resource conservation purposes. New floor drain structure diagram is designed as follows.

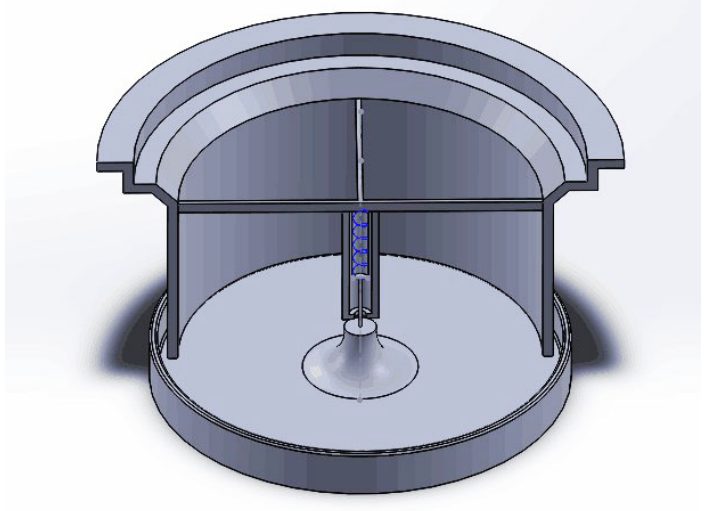

\subsection{Working principle.}

Fig. 1 New floor drain structure diagram

When water flows down, the spring is stretched. In this case the lower end of the spring with a mechanical load-bearing device, can ensure that the spring is not overstretched. Water flows through the small shallow floor drain core base closure inflow sewer pipe.Working process is shown in Figure 2.

When there is no water flow, greater than the gravitational force of the spring base, spring contraction, re-equilibrium state, this time in shallow water seal floor drain core of the state, raising the floor drain airtight, to ensure that the floor drain deodorant performance.Working process is shown in Figure 3.

With the floor drain is not used for a long time, the base of the gradual evaporation of water, a further contraction in the spring, the base in contact with the floor drain outside of the core, this time for a simple mechanical seal, still play the role of deodorant.Working process is shown in Figure 4. 


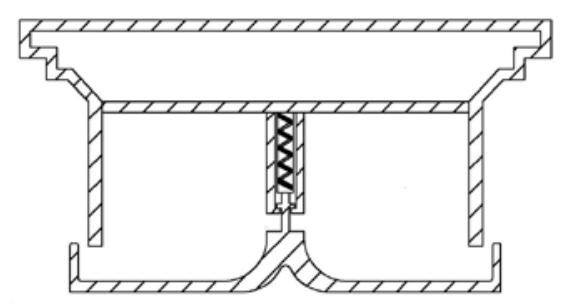

Fig. 2 Drain properly

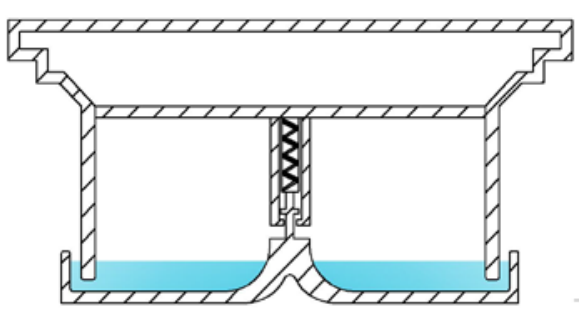

Fig. 3 Water-sealed effect

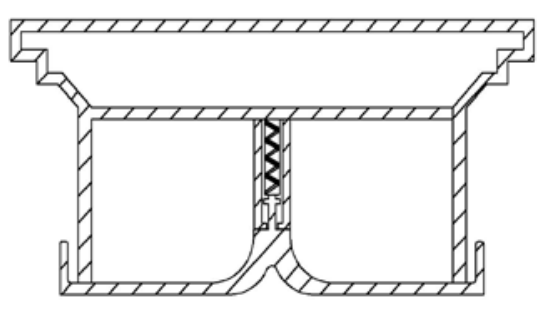

Fig. 4 Spring action

\section{Innovation}

Liquid seal means: Take hemisphere bowl, to ensure water can be stored in a certain premise, to reduce the accumulation of dirt, while the streamlined surface, reducing the direct impact of the drainage of water when the core of the floor drain, floor drain indirectly prolong life.

Machinery: Spring retractable, the liquid seal means water storage, water storage by the gravitational influence of the spring deformation changes, so feel free to keep the water seal floor drain, not using local leak fluid sealing device cause the water dried up, the spring is fully retracted, as a single mechanical closed state.

Spring set: To ensure that the spring will not be overly stretched, providing a barrier at the bottom of the spring, the spring can no longer continue elongation elongation to a certain length, the spring and avoid direct contact with the water part, so no hair and wound spring situation eroded, thus preventing clogging and protected springs purposes.

Base design: Inverted V-shaped base design, reduce weight, indirectly extend the life of the spring.

\section{Experiment}

The new floor drain with several representative floor drain on the market comparative experiments are carried out on water seal height test, drain flow test, self-cleaning ability test and seal stability test. The experimental method of self-cleaning ability test is: Take 20 cotton ropes, 10 to $50 \mathrm{~cm}, 10$ roots are $5 \mathrm{~cm}$, used to simulate the boys and girls of hair, floor drain into the core portion, poured into 1L of water was observed after the water clean, and the residual amount of cotton ropes was repeated three times to calculate the average the less residual lint, prove self-cleaning ability the better. The experiment results are shown in the tables below.

Table 1 Water seal height test

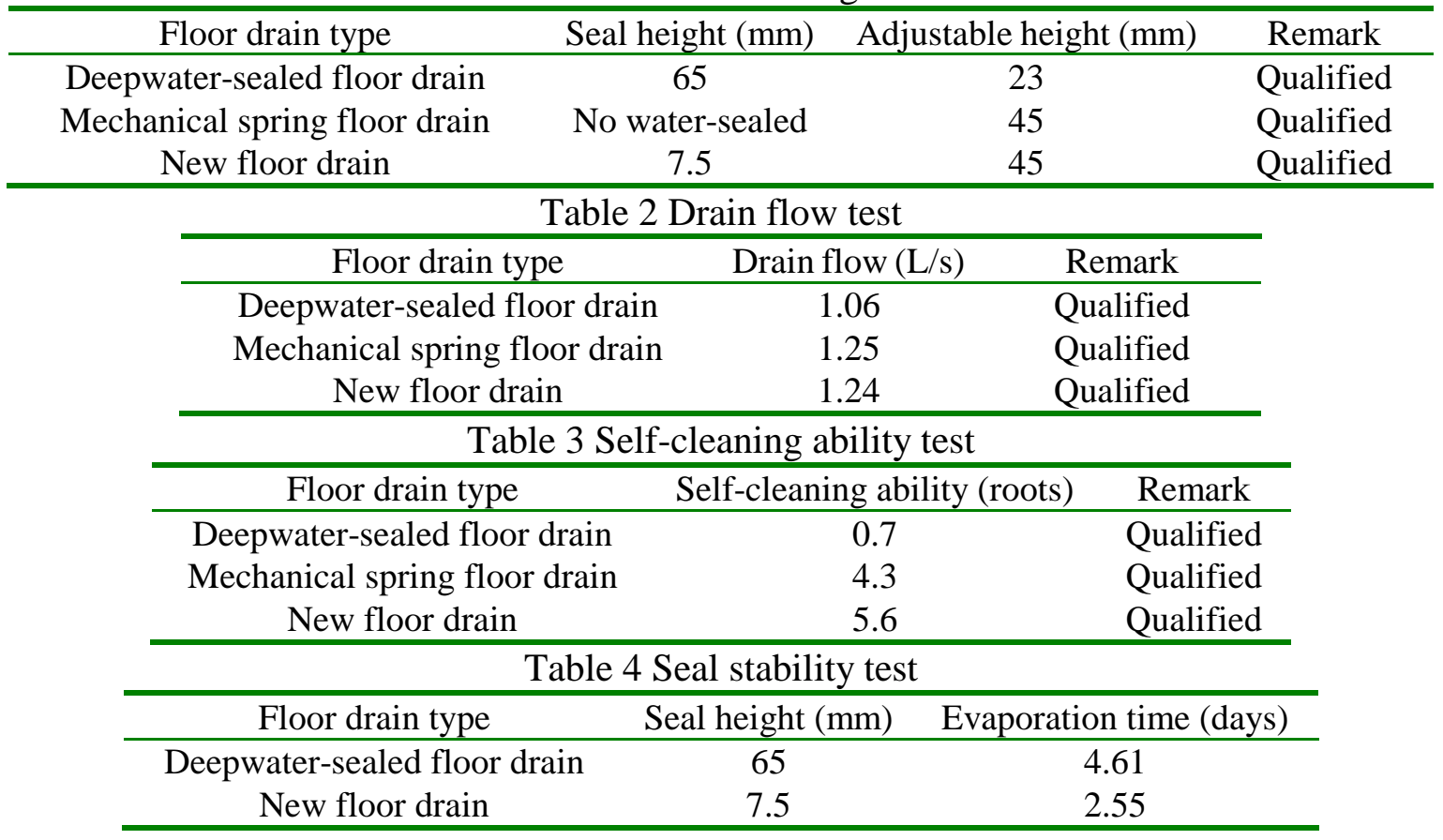


For analysis of the experimental results, the family as an example: If a short trip two days, the deepwater-sealed floor drain and a new floor drain deodorant Seal can be; if long-term travel for 7 days, the deepwater-sealed floor drain has evaporated and no odor, while the new floor drain still mechanical Spring deodorant. From the experimental results, we can see that the new floor drain on the basis of compliance with national standards, the drainage performance, since the ability to clean and deodorant effects of existing floor drain than the market there is a big advantage.

\section{Summary}

The new floor drain has a positive Energy Saving and Emission Reduction meaning. First, extend the life of the floor drain, reducing the number of replacement floor drain, reducing the replacement rate, improve economic efficiency; second, to improve the deodorant properties, optimized emissions at home, to a certain extent, reduce human illness possibilities, while reducing maintenance costs and avoid waste generation due to the maintenance of human, material, financial and other resources; third, to improve drainage performance, and they avoid the clear floor drain caused by the waste of water resources.

China National Engineering Research Center for housing and living conditions for 383 households in the household survey, a total of 252 residents have returned home, odor phenomenon, namely the presence of $65.8 \%$ of the housing problem, and return the site odor floor drain accounting for $59.13 \%$, a total of 149. This shows floor drain deodorant poor performance issues plagued the healthy life of the residents. The new floor drain is a positive response to the state policy in the floor drain performance has been significantly improved, there are in the floor drain on the market, reducing replacement rates and improved service life, while the cost of production compared to the original will be no major changes, so has the cost-effective promotion and strong features. Therefore, the new floor drain has a strong market competitiveness. It is efficient, simple, environmentally friendly, energy saving effect is remarkable, can be used in residential, hotels, office buildings, schools, hotels and other residential and public buildings of the bathroom and kitchen, has great market space and promotional value, with a good prospect.

\section{References}

[1]. Ying Zhang, Xuewei Li, Lei Zhang, et al. Performance Testing of several typical floor drains. WATER \& WASTEWATER ENGINEERING. Vol. 34 (2008) No. 4, p. 90-92.

[2]. Qiaohong Dai. Talking about the importance of modern home design floor drain. Architectural Engineering Technology and Design. 2015. No. 7, p. 338.

[3]. Ruoying Ding, Deming Liu, Xu Gong, et al. Building drainage performance tests commonly used to drain the main study. Fujian Construction Science \& Technology. 2014. No. 6, p. 82-84.

[4]. Information on: http://baike.baidu.com/subview/546585/546585.html 